British Association, has once more raised a perennial problem in scientific discussion, which is of no little public interest. The methods of the B.B.C. must be above the suspicion of propagating error, especially in relation to the advance of scientific discovery. Unfortunately, the field of research to which Prof. Childe refers has been in the past the happy hunting ground of the irresponsible theorist. In certain branches of archæological investigation the apparent familiarity of the terminology and subject-rnatterthe character and purpose of objects of everyday use in the life of the past, and the inferences as to cultural and racial contact to be drawn from themnot only lend themselves to speculation, but also the more startling and sensational the exposition, the more readily it commends itself as matter likely to be of interest to the public, to those who control the machinery of publicity, the lay Press and organizations, of which the B.B.C. is the most important, engaged in the unofficial education of the public. The obvious remedy that the B.B.C. should be advised by a committee of scientific men, and that other organizations and the lay Press should consult expert opinion in order to eliminate the danger of error, is open to the imputation of stifling progress in favour of orthodoxy. The only remedy is full and free discussion without favour, after an impartial statement of controversial points at issue.

\section{Jupiter's Satellites}

Posimions of the newly discovered Satellite $\mathrm{x}$ are available from July 6 to August 1, but the interval is too short for the computation of an orbit with any degree of certainty. A preliminary investigation, however, suggests that the object is at a distance of about 7 million miles from Jupiter, its motion being direct. Whether it is just inside the orbit of vi or outside that of VII is open to doubt, but further observations will enable computers to decide this point. Observations of Satellite XI are available from July 30 to August 1, but it is impossible to compute an orbit from such data. From the figures it is conjectured that the body cannot be less than 10 million miles from Jupiter, and so it certainly lies outside vIr, but there is nothing at present to show that it does not lie outside Ix.

These preliminary investigations were made by Dr. M. Davidson, who assumed, in the computation of the orbit of Satellite $\mathrm{x}$, that this was practically circular. While going to press a Harvard Card announces that two different orbits for Satellite $\mathbf{x}$ have been computed, the results of which have been communicated by Prof. E. I. Yowell, Cincinnati Observatory. The figures in round numbers are as follows: The first orbit, which indicates that the motion of the satellite is direct, has a very high eccentricity, 0.6362 , the semi-major axis being $5,900,000$ miles. This implies that the satellite makes its closest approach to its primary at a distance of $2,150,000$ miles, its greatest distance being $9,650,000$ miles. The other orbit shows an eccentricity 0.6207 , motion retrograde, and the semi-major axis $18,310,000$ miles. If this be correct, the satellite would approach Jupiter to a distance of $6,945,000$ miles, and would recede to $29,675,000$ miles, the time to complete a revolution being more than $2 \frac{3}{4}$ years. The fact that two such diverse orbits can be deduced from the same data shows the great difficulty, as already pointed out, of attaching much importance to the elements which are based upon a short time interval.

\section{Inland Ice Field in Alaska}

A BuLcetin of the National Geographic Society of America announces that an expedition, under the auspices of Harvard University and of the National Geographic Society, and under the leadership of $\mathrm{Mr}$. Bradford Washburn, has made, during the course of aeroplane flights, the important discovery of a vast inland ice field in Alaska. The ice is hemmed in by a coastal range of mountains with peaks reaching 10,000-19,000 ft. above sea-level. This range stretches from the Copper River Valley above Cordova to the Alsek River Valley in the Yukon. Most of the ice lies athwart and to the west of the Alaska-Canada boundary line, where it turns north to the Arctic Ocean. The ice thus forms a barrier to land communication between the south "panhandle" of Alaska and the major part of the territory in the north. It is stated that the ice field covers a stretch of territory 235 miles long. It is in effect so extensive as to constitute an ice reservoir which provides the source of large outflowing glaciers, including the Bering and Malaspina glaciers, the immense size of which-they are 30 and 50 miles wide respectively-is now accounted for. This part of Alaska (which possesses the conditions favourable to glacier formationnamely, high altitude, low temperature and high precipitation) thus contains the largest known ice fields outside the polar regions. It is a remarkable feat that an expedition of only four men should have succeeded in photographing 1,500 square miles of territory in a country peculiarly difficult of access. They have also carried out geological work in the St. Elias Range.

\section{Solar Activity and Radio Communication}

Is the speech made by the Postmaster-General, Major Tryon, at a luncheon of the Newcastle-onTyne Chamber of Commerce, he announced that the Post Office, after consultations with the American telephone authorities, is constructing a special radioreceiving station to combat the intense sunspot activity which is expected to interfere seriously with world-radio communications in 1940 . The longdistance international radio-telephone services are mainly operated on short wave-lengths, and are found to be particularly susceptible to serious interference at periods of great sunspot activity. This has been proved by the graphs at short-wave reception stations, and the connexion between solar flares causing sunspots and fade-outs and magnetic disturbances has been clearly established. Approximately, they appear to follow an eleven-year cycle, a disturbance being due in 1940, and owing to the enormous 